\title{
Argumentação no Ensino de Biologia: uma experiência no ensino médio
}

Marcos Leonardo Martins Silva marcos.martins@ifrn.edu.br

\section{orcid.org/0000-0002-2255-1474}

Universidade Federal do Rio Grande do Norte (UFRN), Natal, RN, Brasil

Márcia Gorette Lima da Silva marciaglsilva@yahoo.com.br Orcid.org/0000-0002-8114-0704 Norte (UFRN), Natal, RN, Brasil

\section{RESUMO}

O objetivo deste artigo é relatar uma experiência para desenvolver uma habilidade de pensamento de alta ordem, a argumentação, como parte de uma das práticas epistêmicas (a avaliação do conhecimento), em alunos da educação básica. Participaram deste estudo 16 alunos do curso técnico integrado em informática do Instituto Federal do Rio Grande do Norte - IFRN - Campus Macau, em aulas do componente curricular de Biologia. Para atender aos objetivos, elaboramos uma atividade abordando os elementos de um argumento e os critérios científicos da descoberta da estrutura do DNA por meio de um roteiro orientador e de um texto histórico e, posteriormente, avaliamos os textos argumentativos desenvolvidos pelos alunos. Para tal análise utilizamos o Padrão de Argumento de Toulmin. Os participantes, organizados em grupos de 4 alunos, elaboraram durante a intervenção textos argumentativos a partir do modelo de Toulmin. Considerando a análise dos argumentos escritos por cada um dos quatro grupos, observamos que os alunos apresentaram Conclusões (C) coerentes, com certa limitação em relação ao conteúdo disciplinar em sua Justificativa (W), e que a principal dificuldade apresentada foi em relação à compreensão dos conceitos dos elementos do argumento, principalmente na distinção entre os Dados (D) e Apoio (B). A experiência aqui relatada busca sinalizar a importância do ensino da argumentação na educação básica, principalmente como gatilho para o desenvolvimento de habilidades de pensamento de alta ordem. Os resultados revelaram direcionamentos importantes, com destaque à importância da implementação contínua de atividades que priorizem o desenvolvimento da argumentação em sala de aula, o valor das atividades colaborativas para a aprendizagem coletiva e individual e a relevância de uma análise da validade das alegações para o conteúdo disciplinar da Biologia.

PALAVRAS-CHAVE: Argumentação. Ensino de Biologia. Padrão de Argumento de Toulmin. 


\section{INTRODUÇÃO}

A dinâmica atual das aulas de Biologia tem ofertado algumas oportunidades para o desenvolvimento de práticas argumentativas que priorizem a produção, comunicação e avaliação de conhecimento científico em sala de aula (DAWSON; VENVILLE, 2010; JIMÉNEZ-ALEIXANDRE, 2014; JIMÉNEZ-ALEIXANDRE; BUGALLO RODRÍGUEZ; DUSCHL, 2000). Driver, Newton e Osborne (2000) afirmam que, para promover uma educação científica adequada para os jovens, é necessário reconceitualizar as práticas do ensino de ciências de maneira a retratar o conhecimento científico como uma construção social, sobretudo em virtude de que uma das atividades centrais dos cientistas é a prática argumentativa, portanto, os autores alegam que a argumentação deve ter alta prioridade em aulas de ciências e desempenhar um papel central na educação científica. Os autores também enfatizam que intervenções realizadas em aulas de ciências, além de promover a melhoria das habilidades de argumentação dos jovens, devem "melhorar os conhecimentos, a consciência e a competência dos professores na gestão da participação dos alunos na discussão e na argumentação" (DRIVER; NEWTON; OSBORNE, 2000, p. 309).

Nas últimas décadas, esse importante insight sobre o papel da linguagem em nível de sala de aula tem direcionado algumas práticas educativas para a investigação científica como forma de promover o debate e a argumentação, priorizando o fazer e o aprender científico, desenvolvendo um entendimento sobre a ciência e sua linguagem ao envolver os alunos em práticas que tenham foco no discurso, através de uma série de atividades estruturadas para este fim (DUSCHL; OSBORNE, 2002).

O presente trabalho corresponde a um recorte de uma pesquisa desenvolvida no âmbito do Mestrado Profissional em Ensino de Ciências Naturais e Matemática da Universidade Federal do Rio Grande do Norte, e trata de algumas inquietações surgidas a partir das leituras e discussões realizadas no nosso grupo e de nossa vivência como professor de Biologia. $O$ foco do nosso projeto foi delimitado em um panorama que buscasse uma reflexão sobre as possíveis contribuições do ensino de práticas argumentativas em aulas de Biologia como forma de solucionar dificuldades de aprendizagem dos alunos em determinados conteúdos do conhecimento disciplinar no ensino médio, com o objetivo de trabalhar atitudes científicas com os alunos, especificamente desenvolver a habilidade de argumentação dos mesmos, situada nas práticas epistêmicas relacionadas à produção, comunicação e avaliação do conhecimento (KELLY, 2008).

Enfatizamos a argumentação em nossa pesquisa considerando sua atual importância no campo do ensino de ciências, portanto, nos preocupamos em estudar o processo de como se constrói as relações de discursos entre estudantes e/ou professores. Jiménez-Aleixandre e Erduran (2007, p. 13) definem a argumentação como "parte do discurso através do qual, alegações de conhecimento são individualmente ou de maneira colaborativa construídas e avaliadas à luz de evidências empíricas ou teóricas", e é justamente nesse aspecto que desenvolvemos nosso trabalho, com foco nos processos de como os alunos avaliam e justificam o conhecimento científico no contexto do ensino de Biologia, por entendermos que construir um argumento não se trata somente de apresentar uma alegação, mas de fundamentar sua justificativa em dados e 
evidências e submetê-la à avaliação dos pares - é compreender que essas práticas são subsídios imprescindíveis na construção do conhecimento científico.

Duschl e Osborne (2002), considerando a possibilidade da inclusão da argumentação na escola e a existência de diversos enquadramentos para sua análise, sinalizam a necessidade de se investigar se o uso regular da argumentação em aulas de ciências pode levar a ganhos significativos no desenvolvimento conceitual e raciocínio cognitivo na ciência. Estes autores destacam que tais pesquisas podem partir de estudos de caso com um grupo de crianças para abordagens maiores e mais experimentais.

No presente manuscrito buscaremos apresentar uma breve revisão bibliográfica sobre a argumentação no ensino de ciências, relataremos nossa experiência sobre a implementação desta prática em aulas de Biologia e discutiremos algumas considerações sobre os direcionamentos deste estudo, assim como o material elaborado para a intervenção.

\section{A ARGUMENTAÇÃO NO ENSINO DE CIÊNCIAS}

Até o final da década de 1990, os professores de ciências despendiam pouca ou nenhuma atenção à argumentação, o que pode ter contribuído para o estabelecimento de falsas impressões, por parte dos alunos, sobre a Ciência e como o conhecimento científico é construído e validado, e, consequentemente falhando em apoderar os mesmos com a competência para avaliar criticamente alegações de conhecimento, advindas tanto da comunidade científica quanto do julgamento de questões sociocientíficas do dia a dia (DRIVER; NEWTON; OSBORNE, 2000).

Essa mudança de campo de estudo no ensino de ciências direcionou o foco das pesquisas sobre o papel da linguagem e comunicação na construção do conhecimento científico e para o processo cognitivo coletivo (JIMÉNEZALEIXANDRE, 2007). Neste contexto, vários estudos se dedicaram à implementação da argumentação nos processos educacionais, com destaque a importância de ensinar aos alunos a usar, avaliar e criticar evidências, tanto através da argumentação escrita quanto no discurso falado (KELLY; REGEV; PROTHERO, 2007).

A emergência na pesquisa sobre a argumentação nos processos educacionais, ratificada pelas políticas educacionais em vários países, levanta a importância da aprendizagem dos alunos em como usar, avaliar e criticar evidências, mais especificamente a capacidade de avaliar o conhecimento (KELLY; REGEV; PROTHERO, 2007). Considerando os modos em que o conhecimento é construído e justificado por uma comunidade através de práticas sociais e viabilizadas através de padrões em ações relacionadas ao conhecimento, Kelly (2008, p. 99) caracteriza essas ações como práticas epistêmicas e as definem como "maneiras específicas em que membros de uma comunidade propõem, justificam, avaliam e legitimam alegações de conhecimento dentro de um enquadramento disciplinar". Na mesma direção, Jiménez-Aleixandre e Brocos (2015) explicam que, apesar da argumentação corresponder, sobretudo, à avaliação do conhecimento, os três tipos de práticas epistêmicas propostas por Kelly (2008) estão diretamente relacionadas entre si. Para que os estudantes possam explicar um dado fenômeno, é necessário que utilizem conhecimentos 
científicos de modo que possam construir e criar modelos, além de avaliar os critérios que fundamentem a explicação (JIMÉNEZ-ALEIXANDRE; DÍAZ BUSTAMANTE, 2003). Assim, a avaliação do conhecimento científico enquanto prática epistêmica (o que assumimos como argumentação) implica em utilizar conceitos científicos, submeter à comprovação, tirar conclusões com base científica e comunicar (SILVA; MARQUEZ; OLIVERAS, 2016).

A partir da necessidade de se priorizar os aspectos sociais no ensino de ciências, Lemke (1990), em seu livro Talking Science, se concentra na análise de como os processos de comunicação em sala de aula podem criar e sustentar situações sociais, caracterizadas pelo autor como uma série de relacionamentos e expectativas entre seus participantes (alunos, professor e/ou comunidade), enfatizando que aprender ciência é aprender a falar ciência e posiciona a linguagem como papel fundamental na aprendizagem enquanto processo sociocultural. $O$ aprendizado da argumentação e outras práticas epistêmicas são fundamentadas em visões de aprendizagem socioconstrutivistas e, atualmente, impõe um desafio na pesquisa educacional através de projetos, implementações e avaliações de sequências de ensino que inovem nos processos de ensinoaprendizagem (JIMÉNEZ-ALEIXANDRE, 2007).

Assim, na última década, diversos grupos internacionais como o Mind The Gap (Universidade de Bristol), RODA (Universidade de Santiago de Compostela) e IDEAS (King's College London) têm dedicado esforços no desenvolvimento de recursos e estratégias para a implementação de ambientes de aprendizagem que promovam a argumentação e a aprendizagem de práticas científicas discursivas. Dawson e Venville (2010) apontam que um dos resultados essenciais da educação científica na escola é o de capacitar os alunos a usar a sua compreensão sobre ciência para contribuir para o debate público e tomar decisões informadas e equilibradas sobre questões sociais e científicas que possuem impacto em suas vidas.

Nesta perspectiva, diferentes trabalhos buscaram/buscam avaliar as contribuições da argumentação para o ensino de ciências, tendo uma parte expressiva deles utilizado o Padrão de Argumento de Toulmin (2006) como marco teórico, tanto para a representação da estrutura dos argumentos quanto para análise da qualidade da argumentação em sala de aula (BERLAND; REISER, 2009; ERDURAN et al., 2004; EVAGOROU; JIMÉNEZ-ALEIXANDRE; OSBORNE, 2012; EVAGOROU; OSBORNE, 2013; JIMÉNEZ-ALEIXANDRE et al., 2000; MOTOKANE, 2015; SASSERON; CARVALHO, 2008, 2011; VERHEIJ, 2005; VON AUFSCHNAITER et al., 2008; ZOHAR; NEMET, 2002).

Figura 1 - Esquema do Padrão de Argumento de Toulmin

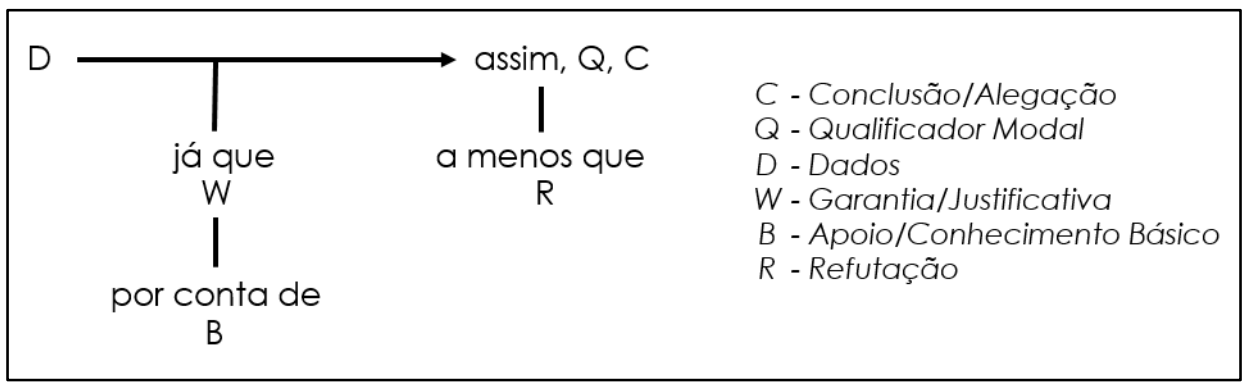


O modelo de Toulmin para a análise de argumentos foi desenvolvido com o intuito de descrever a argumentação na prática, longe dos esquemas da lógica formal, e funciona como uma ferramenta útil para a análise do discurso em situações de construção de conhecimento em sala de aula, sendo seu foco principal justificar alegações cuja validade depende diretamente da coerência e fundamentação em dados e apoio (JIMÉNEZ-ALEIXANDRE; ERDURAN, 2015). O Padrão de Argumento de Toulmin é composto por seis elementos, sendo três principais: conclusão (ou alegação) (C), dados (D) e garantia (ou justificativa) (W); e três auxiliares: apoio (ou conhecimento básico) (B), qualificador modal (Q) e refutação (R).

Pinochet (2015), em sua pesquisa sobre o modelo de Toulmin, faz uma reflexão sobre a importância do ensino da argumentação em aulas de ciências, apontando como contribuições relevantes ao processo de ensino-aprendizagem a introdução à cultura científica através de competências argumentativas e o desenvolvimento de visão crítica e reflexiva sobre a construção do conhecimento científico. Porém, deixa claro que a maioria dos trabalhos consultados sinaliza que tais resultados requerem estratégias pedagógicas que as promovam mediante um trabalho contínuo durante algum tempo. Apesar de sua importância e contribuições, o modelo de Toulmin possui diversas limitações para uma análise mais aprofundada, principalmente no que diz respeito à natureza dialógica do argumento, sendo mais adequado para análise e classificação dos elementos primariamente monológicas (JIMÉNEZ-ALEIXANDRE; ERDURAN, 2015).

A proposição de métodos ou instrumentos para a análise da qualidade da argumentação (falada ou escrita) tem sido um componente recorrente em diversos trabalhos (ERDURAN; SIMON; OSBORNE, 2004; JIMÉNEZ-ALEIXANDRE; BUGALLO RODRÍGUEZ; DUSCHL, 2000; OSBORNE; ERDURAN; SIMON, 2004; SAMPSON; CLARK, 2008, 2009; ZOHAR; NEMET, 2002). Erduran (2007) afirma que o enfoque metodológico para análise da argumentação depende diretamente da questão de pesquisa, portanto, depende também do contexto escolar que se pretende utilizar como "geradora" da prática argumentativa. Isto é, a maneira de comprovar as potencialidades de uma sequência de ensino reside na possibilidade de análise da argumentação por ela proporcionada, na evolução da qualidade argumentativa dos alunos durante as atividades.

KolstøeRatcliffe (2007), considerando os diferentes padrões de diálogos gerados durante a prática argumentativa em sala de aula, alertam sobre a necessidade de que o professor esteja ciente da importância de se projetar o ambiente de aprendizagem e contexto educacional de acordo do tipo de diálogo que se espera dos alunos, transmitindo uma imagem adequada da ciência, ou seja, identificando as características dos discursos argumentativos. Essa preocupação é recorrente em abordagens da prática científica em sala de aula tendo em vista as concepções positivistas simplistas dos alunos acerca da Ciência (LEDERMAN, 1992).

Nosso trabalho considera a perspectiva de pesquisa educacional descrita por Jiménez-Aleixandre (2007) sobre o entendimento de que a sala de aula constitui um sistema complexo de relacionamentos e interações, e, portanto, nos concentramos na apreciação de práticas epistêmicas dentro de sala de aula (KELLY, 2008; SANDOVAL; REISER, 2004), com interesse específico na promoção, 
análise e relato da argumentação proporcionada pelas atividades desenvolvidas e implementadas.

As interações discursivas em sala de aula podem ser extremamente úteis para a investigação de diversos aspectos da linguagem e comunicação dos alunos durante aulas de ciências (SASSERON, 2013). Em nossa pesquisa, destacamos como centrais para a avaliação da qualidade da argumentação dos alunos os aspectos cognitivo-conceituais, os epistêmicos e sociais (SAMPSON; ENDERLE; WALKER, 2011) e constatamos a necessidade de criar oportunidades para que os alunos participem de práticas que priorizem o pensamento crítico em sala de aula, revelado através da argumentação. Mesmo assim, devemos levar em consideração, o que pondera Kuhn (2010), ao reconhecer que o discurso argumentativo é um processo complexo, em que, mesmo nos casos mais simples como um discurso diádico, demanda o processamento simultâneo da contribuição do interlocutor e a antecipação da própria resposta sucessivamente para que seja estabelecida uma sequência em turnos.

\section{O DESENHO DO ESTUDO: CONTEXTO E PERCURSO METODOLÓGICO}

Nosso estudo foi desenvolvido no Campus Macau do Instituto Federal de Educação, Ciência e Tecnologia do Rio Grande do Norte - IFRN, com 16 estudantes do 3 o ano do curso técnico de informática integrado ao ensino médio na disciplina de Biologia. Nesta intervenção, priorizamos o desenvolvimento da argumentação escrita (SAMPSON; GROOMS; WALKER, 2011) abordando uma temática relacionada ao conteúdo de Genética.

A finalidade deste estudo foi proporcionar um ambiente de aprendizagem que inclua atividades que favoreçam o desenvolvimento da argumentação escrita como prática epistêmica de avaliação do conhecimento a partir da análise de dados e da leitura de um texto histórico. Para tanto, como objetivos específicos (a) elaboramos e aplicamos uma atividade para ensinar os alunos a argumentar; e (b) avaliamos os argumentos escritos produzidos pelos alunos.

O material elaborado (Figura 2) é parte de uma sequência de atividades em desenvolvimento com o objetivo de ensinar argumentação de maneira explícita para alunos do ensino médio e foi adaptado do trabalho desenvolvido por Sampson et al. (2014) sobre a estrutura do DNA.

A aula, planejada para duas horas-aula, foi dividida em dois momentos. $\mathrm{O}$ primeiro momento da intervenção teve como foco a introdução do conteúdo por meio de uma aula expositiva dialogada, no qual foram abordados: (a) a construção e validação do conhecimento científico em uma dada comunidade científica; (b) informações sobre as pesquisas que levaram à descoberta da estrutura do DNA e suas implicações para a pesquisa genética decorrente; (c) a importância do uso do argumento como parte da validação do conhecimento científico, além dos elementos que constituem um argumento conforme o modelo de Toulmin (2006).O segundo momento foi reservado à aplicação de uma atividade com o objetivo de desenvolver a habilidade da argumentação escrita dos alunos. A turma foi dividida em quatro grupos de quatro alunos, onde cada grupo deveria utilizar as informações e discussões apresentadas durante o primeiro momento para elaborar um argumento escrito seguindo o Padrão de Argumento de Toulmin para responder a seguinte questão: "Qual a importância 
da estrutura do DNA?". Como material de leitura complementar à atividade, disponibilizamos a tradução do artigo "Estrutura Molecular dos Ácidos Nucleicos" apresentado por Watson e Crick (1953) por servir de subsídio para a consecução da tarefa, além de proporcionar uma aproximação dos alunos com textos históricos.

Figura 2 - Atividade sobre a estrutura do DNA

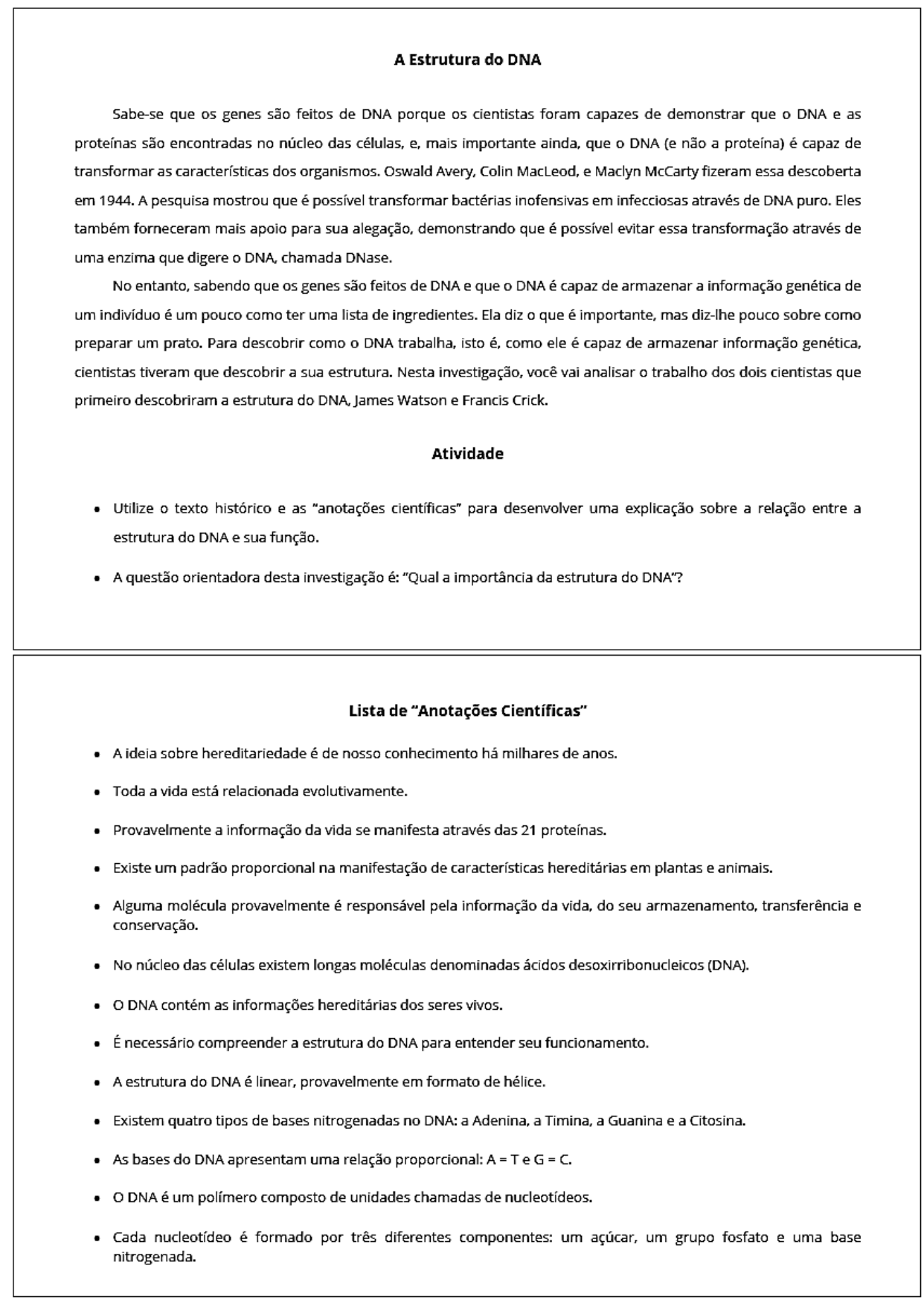

Fonte: Adaptado de Sampson et al. (2014, p. 250-262).

Devido ao enfoque implicitamente qualitativo do que pretendemos analisar neste trabalho, nossa intervenção seguiu elementos de um estudo de caso, tendo em vista a necessidade de observação e relato da experiência e do desempenho dos alunos durante o desenvolvimento das atividades propostas. Além disso, essa 
escolha se deve em virtude das características de um estudo de caso que, conforme afirmam Lüdke e André (1986), prioriza a busca pela descoberta, a interpretação em contexto, a retratação da realidade de forma complexa, a utilização de fontes de informação variadas, generalizações naturalísticas, representações de situações sociais diferentes e/ou conflitantes e a utilização de linguagem acessível.

\section{ANALISANDO OS RESULTADOS}

Apresentamos na aula o contexto histórico e científico da descoberta da estrutura do DNA por James Watson e Francis Crick (1953), levando em consideração o que se sabia na época: o que estava sendo pesquisado, os dados, as evidências e as informações científicas decorrentes dessa investigação.

Para a realização da atividade, fornecemos: folhas de ofício para rascunho e cartolina branca para a montagem do esquema do argumento no modelo de Toulmin; o material da atividade, composto pelas orientações, as "anotações científicas" (em recortes) e o texto histórico de Watson e Crick (1953) sobre a estrutura do DNA. Após a leitura do texto, os alunos deveriam, inicialmente, avaliar e classificar as anotações científicas como Dados/Evidências (D) ou Apoio/Conhecimento Básico (B), e, em seguida, cada grupo, após uma discussão entre os pares, deveria elaborar sua Conclusão/Alegação(C) e Justificativa (W). Após esta etapa, os alunos ficaram livres para circular entre os demais grupos, ouvir a argumentação dos outros e reformular o próprio argumento, como parte da negociação e avaliação do conhecimento (Figura 3).

Figura 3-Construção do argumento a partir do modelo de Toulmin

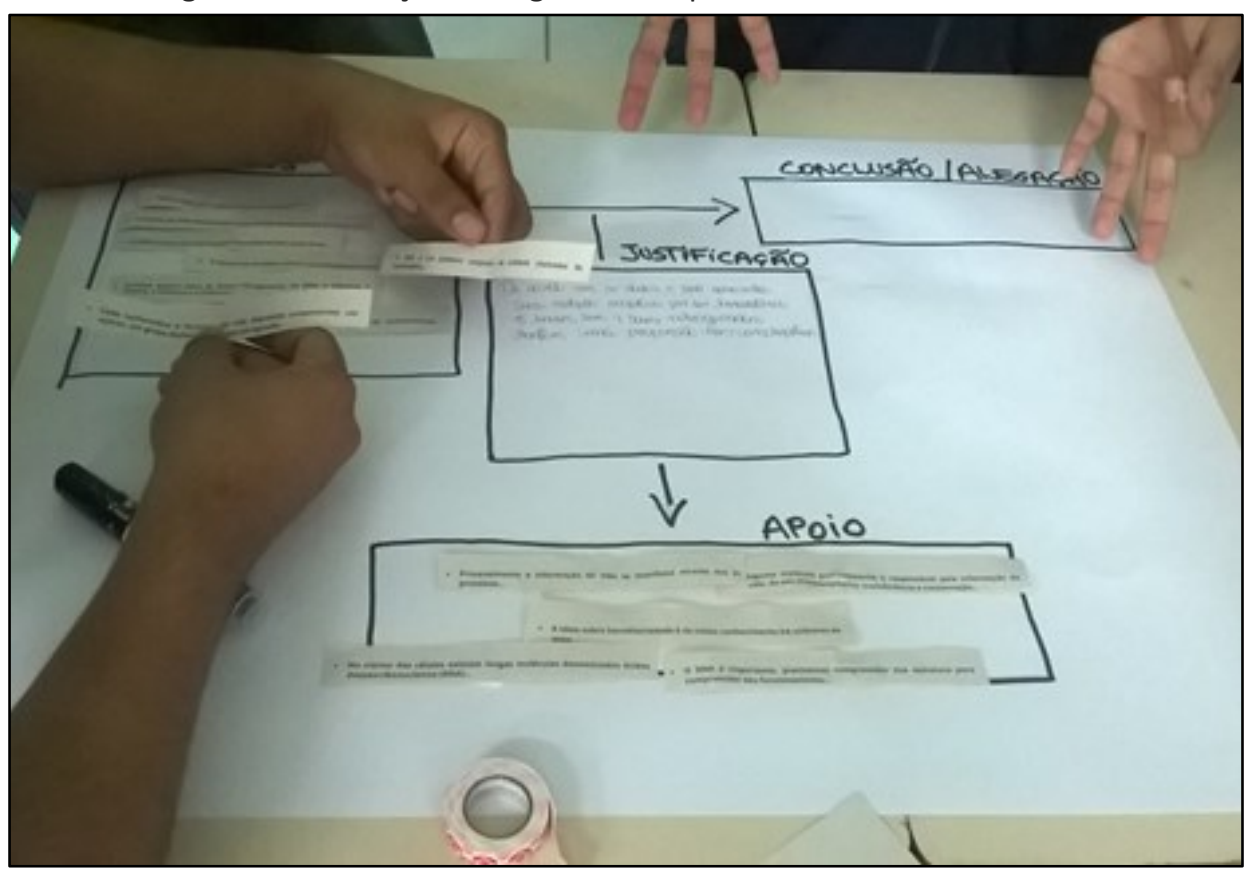

Fonte: Elaborado pelos autores (2016).

Considerando que a proposta da atividade consistiu em ensinar os alunos a utilizar os dados e evidências disponíveis para desenvolver uma explicação sobre a relação entre a estrutura do DNA e sua função através da construção de um 
argumento, de maneira a demonstrar os resultados alcançados com a atividade proposta, apresentaremos a seguir uma análise dos argumentos escritos a partir do que foi elaborado por cada um dos quatro grupos seguindo o padrão de Toulmin.

Figura 4-Argumento do grupo 01 no modelo de Toulmin

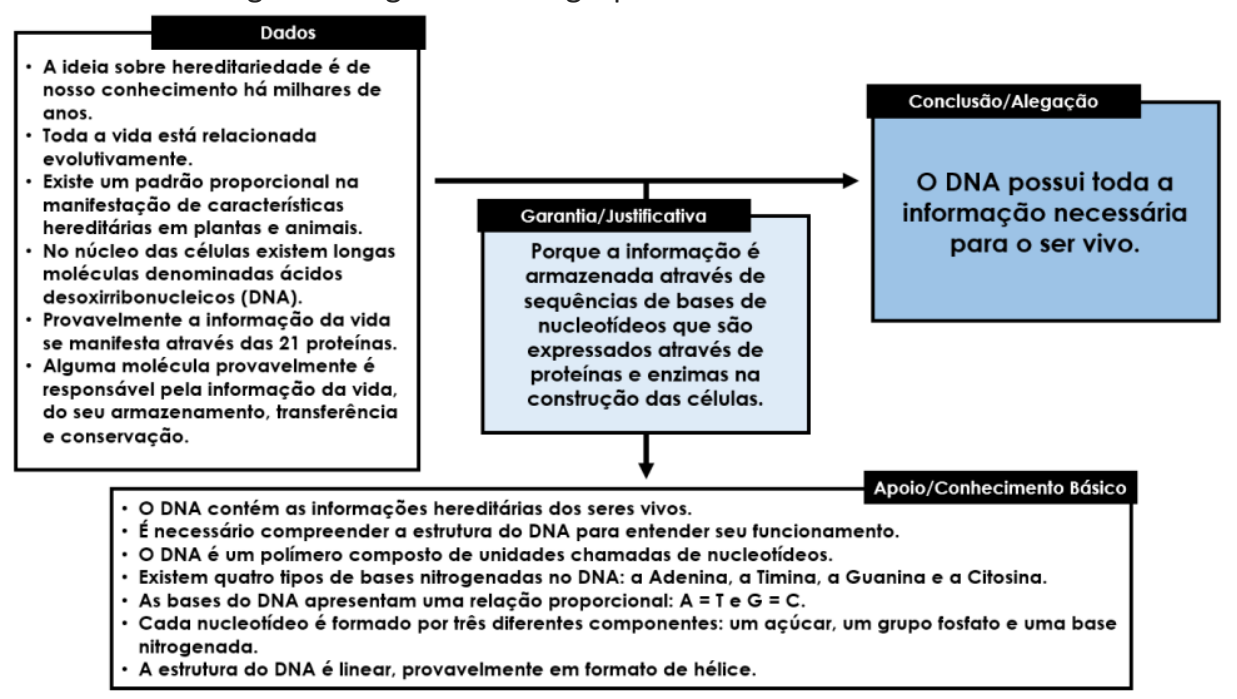

Fonte: Elaborado pelos autores (2016).

O grupo 01 (Figura 4) apresentou a seguinte Conclusão (C) "O DNA possui toda a informação necessária para o ser vivo", a qual tem adequação ao conteúdo e à questão proposta, apesar de não comentar seu caráter hereditário. A classificação do que conta como Dados (D) e o que conta como Apoio (B) foi feita de maneira apropriada. Na Justificativa (W) os alunos relacionaram a estrutura e composição química do DNA à sua função de armazenamento de informação, afirmando que "... a informação é armazenada através de sequências de bases de nucleotídeos...", apoiando-se em dados apresentados no texto de referência e destacando ainda sua função na expressão genética "... expressadas através de proteínas e enzimas na construção das células". Apesar do argumento apresentado estar organizado de maneira adequada, é importante destacar que este grupo não utilizou Qualificadores Modais (Q) associados à Conclusão (C). Outra observação relevante é que este foi o único grupo que solicitou mais informações sobre a diferença entre Dados (D) e Apoio (B), alegando sentirem dificuldades em distingui-los.

O grupo 02 (Figura 5) incluiu em sua Conclusão (C) apenas o aspecto do "... armazenamento das características hereditárias" do DNA, demonstrando um conhecimento superficial sobre sua importância. A Justificativa (W) apresentada busca associar os Dados (D) e o Apoio (B), priorizando a descrição da estrutura do DNA “... organizada através de nucleotídeos em dupla-hélice com fitas complementares", mas sem explicar sua relação com as funções da molécula. Assim como o grupo 01, este grupo também não utilizou Qualificadores Modais (Q) para reforçar a Conclusão(C). Um ponto que chamou atenção é que este grupo confundiu os Dados (D) com o Apoio (B), ou seja, ao tentar classificar as anotações científicas, inverteram, em sua maioria, as posições desses elementos, talvez pelo fato de não terem compreendido o significado destes no argumento. 
Figura 5- Argumento do grupo 02 no modelo de Toulmin

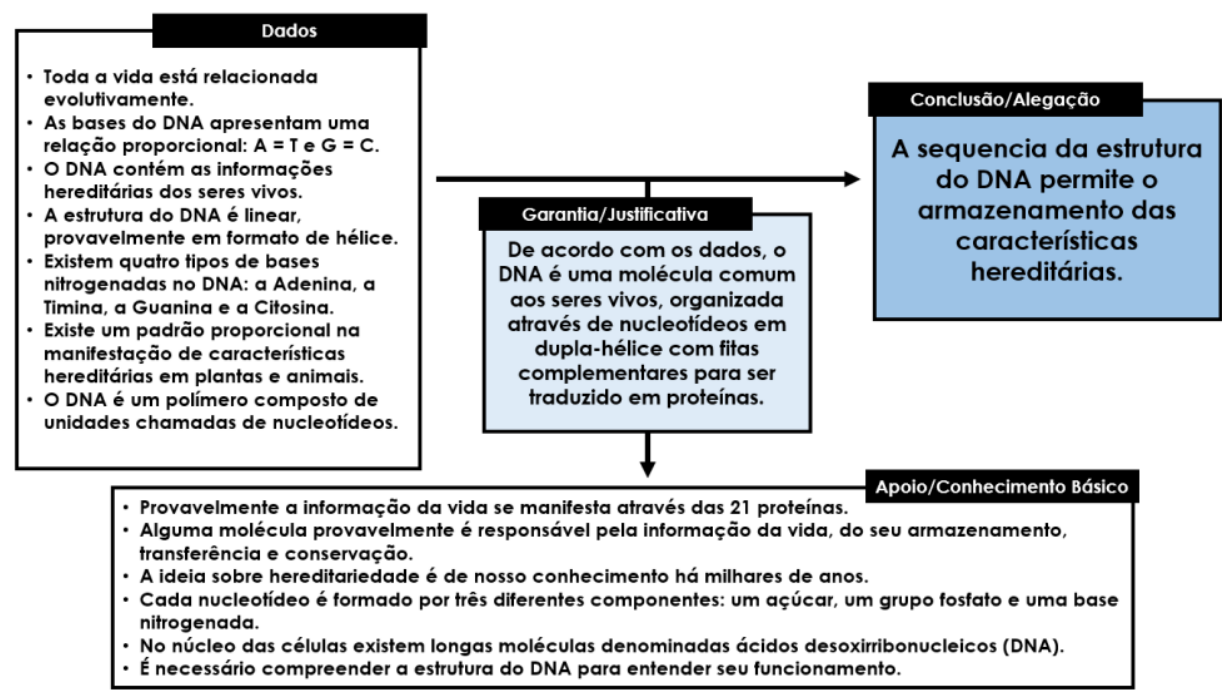

Fonte: Elaborado pelos autores (2016).

O grupo 03 (Figura 6) apresentou uma Conclusão coerente, relacionando a estrutura do DNA ao “... sequenciamento de informações genéticas", porém, a Justificativa (W) é breve e não traz informações do Apoio (B), reproduzindo apenas Dados (D) sem uma interpretação dos mesmos, resumindo a importância da sequência das bases à manifestação das "... características dos seres vivos". Os Dados (D) e o Apoio (B) do argumento são classificados de forma aleatória, provavelmente porque o grupo pode não ter compreendido o significado desses elementos do argumento, e, assim como os demais, este grupo também não utilizou Qualificadores Modais (Q).

Figura 6-Argumento do grupo 03 no modelo de Toulmin

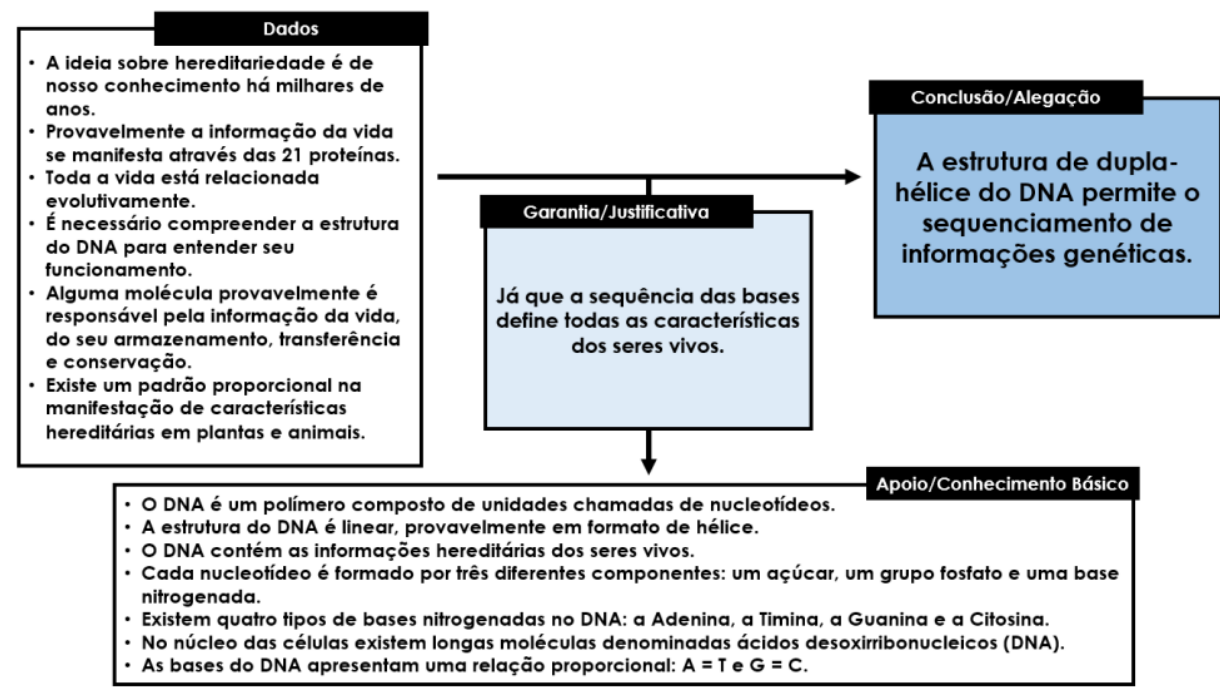

Fonte: Elaborado pelos autores (2016).

O grupo 4 (Figura 7) apresentou uma Conclusão (C) incompleta, tratando apenas da função do DNA como responsável pela expressão genética, como se observa na transcrição "O DNA é responsável pela manifestação das características dos seres vivos". A Justificativa (W) exposta pelo grupo, além de não propiciar uma conexão com a Conclusão (C), apresenta erros conceituais, ao 
explicar que a função de armazenamento de informação genética está associada apenas ao tamanho da molécula e relacionar essa característica à variedade dos seres vivos. Com relação aos Dados (D) e ao Apoio (B), observamos que o grupo buscou um padrão de classificação satisfatório, mesmo apresentando algumas falhas. O grupo também não utilizou Qualificadores Modais (Q). Um aspecto que não consistia nosso objeto de estudo, mas que pode ter influenciado a participação nesta atividade é o fato de um dos participantes deste grupo ser um aluno em mobilidade internacional recém-chegado, o que levou aos demais participantes a promover a sua interação na escola e na cidade, pois em vários momentos observamos nas falas tal intenção.Apresentamos a seguir (Figura 7) o esquema do argumento elaborado por este grupo.

Figura 7-Argumento do grupo 04 no modelo de Toulmin

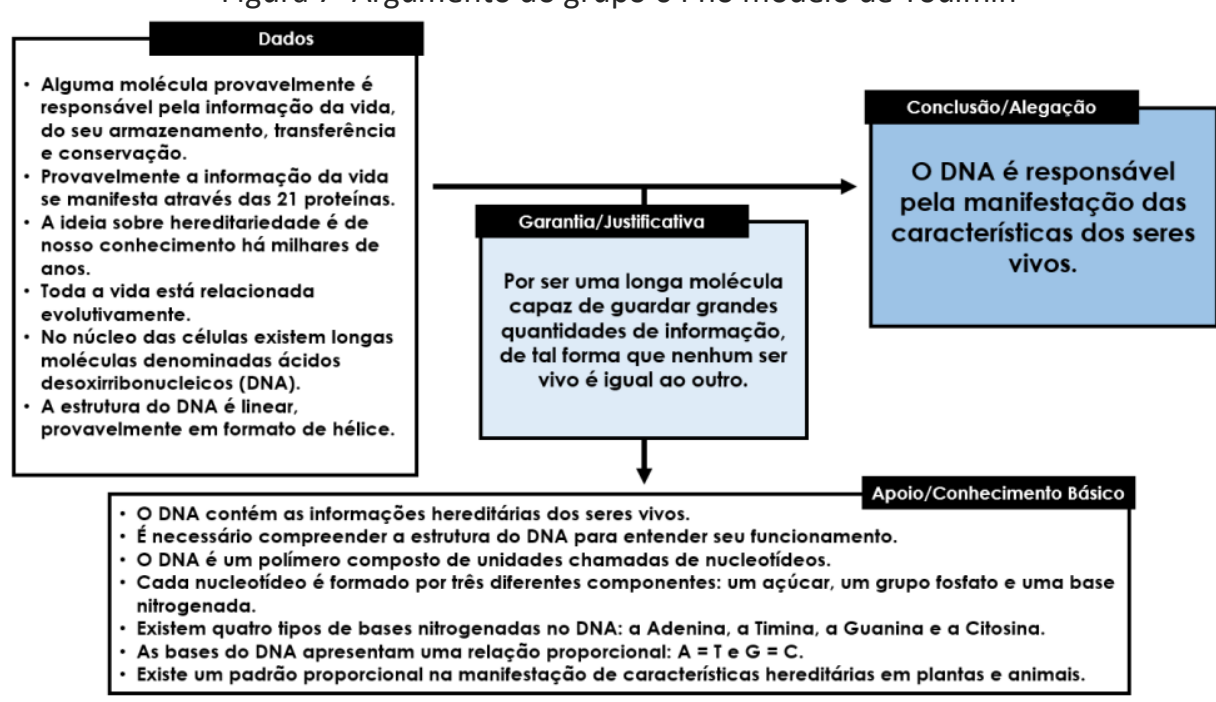

Fonte: Elaborado pelos autores (2016).

De uma maneira geral, os resultados revelaram direcionamentos importantes, já sinalizados em artigos que compõe nosso enquadramento teórico, com destaque à importância das atividades colaborativas para a aprendizagem coletiva e individual (SAMPSON; CLARK, 2009), a necessidade de um instrumento de análise que contemple os aspectos sociais, epistêmicos e cognitivos dos alunos (SAMPSON; CLARK, 2008) e a validade das alegações para o conteúdo disciplinar da Biologia (ZOHAR; NEMET, 2002), além da necessidade da implementação contínua dessa prática para possibilitar uma análise sobre a evolução dos alunos durante determinado tempo (KUHN, 2010).

\section{CONCLUSÕES}

A experiência aqui relatada busca sinalizar a importância do ensino da argumentação na educação básica e, apesar da intervenção pontual, observamos que a maioria dos alunos elaborou uma Conclusão (C) coerente com certas limitações. As principais dificuldades observadas referem-se, principalmente, à identificação das Evidências e Dados (D) e o que conta como Apoio/Conhecimento básico (B), resultados também observados em outros trabalhos (JIMÉNEZ-ALEIXANDRE; BUGALLO RODRÍGUEZ; DUSCHL, 2000; SANDOVAL; REISER, 2004). Outro ponto a ser destacado é que nenhum grupo 
utilizou Qualificadores Modais ( $Q$ ) associados à suas Conclusões (C), o que pode sinalizar que, assim com os Dados (D) e Apoio (B), os conceitos dos elementos do argumento não foram compreendidos pela maioria da classe, o que reforça a necessidade de exemplificar a função de cada elemento em aplicações futuras do material proposto, principalmente em virtude do seu propósito, que é ensinar a argumentação explicitamente. Tal fato já foi sugerido por Duschl (2007), ao indicar uma possível ambiguidade para estes elementos, além da dificuldade em definir "o que conta" como cada um deles.

Como aspecto positivo, destacamos o envolvimento dos participantes nas atividades. Assim, o professor, ao criar oportunidades para que os alunos desenvolvam habilidades argumentativas em sala de aula de uma forma crítica, pode promover o engajamento dos mesmos em debates sobre temas relacionados à Ciência e sobre seus impactos e influências no nosso contexto social. Trata-se não somente de criar essas oportunidades, mas de sequenciar atividades de ensino que propiciem aos alunos habilidades que os permitam investigar, participar, argumentar suas opiniões ativamente em discussões científicas. A adoção de referenciais sobre argumentação para o uso em sala de aula possui potencial para desenvolver práticas epistêmicas como a avaliação do conhecimento e sinaliza a necessidade de mudança no foco do "o que?" para o "como?" e "por quê?", o que pode exigir que o professor apresente novas formas de conhecimento para o diálogo em sala de aula. 


\title{
Argumentation in Biology Education: an experience in high school
}

\begin{abstract}
The aim of this paper is to report an experience to develop a higher order of thinking skill, argumentation, as part of one of the epistemic practices (assessment of knowledge), in students of basic education. The study included 16 students of an integrated technical course in informatics from the Rio Grande do Norte Federal Institute - IFRN - Campus Macau in classes of the curricular component Biology. In order to meet our goals, we developed an activity addressing the elements of an argument and the scientific criteria of the discovery of DNA structure by means of a guiding script and a historical text and, subsequently, evaluating the argumentative texts developed by the students. For this analysis we used Toulmin's Argument Pattern. The participants, organized in groups of four students, developed during the intervention argumentative texts taking into account the model of Toulmin. Considering the analysis of the written arguments by each of the four groups, we noted that the students presented consistent Conclusions (C), with certain limitation regarding the disciplinary content in its Warrants (W), and that the main difficulty presented was regarding understanding the concepts of argument elements, particularly the distinction between Data (D) and Backings (B). The experience here reported seeks to signal the importance of the argumentation teaching in basic education, especially as a trigger for the development of higher-order thinking skills. The results revealed important directions, highlighting the importance of continued implementation of activities that focus on the development of argumentation in the classroom, the value of collaborative activities for individual and collective learning and the importance of an analysis of the validity of claims to disciplinary content of Biology.
\end{abstract}

KEYWORDS: Argumentation. Biology Education. Toulmin's Argumentation Pattern. 


\section{AGRADECIMENTOS}

Agradecemos aos alunos do IFRN que participaram deste estudo e as discussões no Grupo de Estudo "Argumentação no Ensino de Ciências" da UFRN.

\section{REFERÊNCIAS}

BERLAND, L. K.; REISER, B. J. Making sense of argumentation and explanation. Science Education, 93(1), p. 26-55, 2009.

DAWSON, V. M.; VENVILLE, G. Teaching Strategies for Developing Students' Argumentation Skills About Socioscientific Issues in High School Genetics. Research in Science Education, N. 40, p. 133-148, 2010.

DRIVER, R.; NEWTON, P.; OSBORNE, J. Establishing the norms of scientific argumentation in classrooms. Science Education, 84 (3), p. 287-312, 2000.

DUSCHL, R. Science Education in Three-Part Harmony: Balancing Conceptual, Epistemic, and Social Learning Goals. Review of Research in Education, vol. 32, 1: p. 268-291, Feb., 2008.

DUSCHL, R. A.; OSBORNE, J. Supporting and promoting argumentation discourse in science education. Studies in Science Education, 38, p. 39-72, 2002.

ERDURAN, S. Methodological Foundations in the Study of Argumentation in Science Classrooms. In: ERDURAN, S.; JIMÉNEZ-ALEIXANDRE, M. P. (Eds.), Argumentation in science education: perspectives from classroom-based research. (p. 47-69): Springer, 2007.

ERDURAN, S.; SIMON, S.; OSBORNE, J. Tapping into argumentation: Developments in the application of Toulmin's argument pattern for studying science discourse. Science Education, 88(6), 915-933, 2004.

EVAGOROU, M.; JIMÉNEZ-ALEIXANDRE, M.; OSBORNE, J. "Should We Kill the Grey Squirrels?" A Study Exploring Students' Justifications and Decision-Making. International Journal of Science Education, 34 (3), p. 401-428, 2012.

EVAGOROU, M.; OSBORNE, J. Exploring Young Students' Collaborative Argumentation within a Socioscientific Issue. Journal of Research in Science Teaching, 50 (2), p. 209-237, 2013. 
education: perspectives from classroom-based research. p. 91-115: Springer, 2007.

JIMÉNEZ-ALEIXANDRE, M. P.; BROCOS, P. Desafios metodológicos na pesquisa da argumentação em ensino de ciências. Revista Ensaio, Belo Horizonte, v.17 n. especial, p. 139-159, nov., 2015.

JIMÉNEZ-ALEIXANDRE, M. P.; BUGALLO RODRÍGUEZ, A.; DUSCHL, R. A. "Doing the Lesson" or "Doing Science": Argument in High School Genetics. Science Education, 84 (6), p. 757-792, 2000.

JIMÉNEZ-ALEIXANDRE, M. P.; DÍAZ DE BUSTAMANTE, J. Discurso de Aula y Argumentación en la Clase de Ciencias: Cuestiones Teóricas y Metodológicas. Enseñanza de las Ciencias, 21 (3), p. 359-370, 2003.

JIMÉNEZ-ALEIXANDRE, M. P.; ERDURAN, S. Argumentation in science education: an overview. In: ERDURAN, S.; JIMÉNEZ-ALEIXANDRE, M. P. (Eds.), Argumentation in science education: perspectives from classroom-based research. (p. 3-27): Springer, 2007.

JIMÉNEZ-ALEIXANDRE, M. P.; ERDURAN, S. Argumentation. In: GUNSTONE, R. (Ed.) Encyclopedia of Science Education. (p. 54-59) Dordrecht: Springer, 2015.

KELLY, G. J.; REGEV, K.; PROTHERO, W. Analysis of Lines of Reasoning in Written Argumentation. In: ERDURAN, S.; JIMÉNEZ-ALEIXANDRE, M. P. (Eds.), Argumentation in science education: perspectives from classroom-based research. (p. 137-157): Springer, 2007.

KELLY, G. J. Inquiry, Activity, and Epistemic Practices. In: DUSCHL, R. A.; GRANDY, R. E. (Eds.) Teaching Scientific Inquiry: Recommendations for Research and Implementation. (p. 99-117): Sense Publishers, 2008.

KOLST $\varnothing$, S. D.; RATCLIFFE, M. Social Aspects of Argumentation. In: ERDURAN, S.; JIMÉNEZ-ALEIXANDRE, M. P. (Eds.), Argumentation in science education: perspectives from classroom-based research. (p. 117-136): Springer, 2007.

KUHN, D. Teaching and Learning Science as Argument. Science Education, 94, p. 810-824, 2010. 359, 1992. 
LEMKE, J. J. Talking Science: Language, Learning and Values. Norwood, NJ: Ablex, 1990.

LÜDKE, M.; ANDRÉ, M. E. D. A. de. Pesquisa em Educação: Abordagens Qualitativas. São Paulo: E.P.U., 1986.

MOTOKANE, M. T. Sequências Didáticas Investigativas e Argumentação no Ensino de Ecologia. Revista Ensaio, Belo Horizonte, v.17 n. especial, p. 115-137, nov., 2015.

OSBORNE, J.; ERDURAN, S.; SIMON, S. Enhancing the Quality of Argumentation in School Science. Journal of Research in Science Teaching, 41 (10), p. 994-1020, 2004.

PINOCHET, J. El modelo argumentativo de Toulmin y la educación en ciencias: una revisión argumentada. Ciência\&Educação, Bauru, v. 21, n. 2, p. 307-327, 2015.

SAMPSON, V.; CLARK, D. B. Assessment of the Ways Students Generate Arguments in Science Education: Current Perspectives and Recommendations for Future Directions. Science Education, 92, p. 447-472, 2008.

SAMPSON, V.; CLARK, D. B. The Impact of Collaboration on the Outcomes of Scientific Argumentation. Science Education, 93, p. 448-484, 2009.

SAMPSON, V.; ENDERLE, P.; GLEIM, L.; GROOMS, J.; HESTER, M.; SOUTHERLAND, S.; WILSON, K. Argument-Driven Inquiry in Biology: lab investigations for grades 9-12. 1st ed. Arlington, Virginia: NTSA Press, 2014.

SAMPSON, V.; ENDERLE, P. J.; WALKER, J. P. The development and validation of the Assessment of Scientific Argumentation in the Classroom (ASAC) observation protocol: A tool for evaluating how students participate in scientific argumentation. In: KLINE, M. (Ed.), Perspectives in Scientific Argumentation: Theory, practice and research (p. 235-264). New York: Springer, 2011.

SAMPSON, V.; GROOMS, J.; WALKER, J. P. Argument-Driven Inquiry as a Way to Help Students Learn How to Participate in Scientific Argumentation and Craft Written Arguments: An Exploratory Study. Science Education, 95, p. 217-257, 2011. conceptual and epistemic scaffolds for scientific inquiry. Science Education, 88, p. 345-372, 2004. 
SASSERON, L. H. Interações discursivas e investigação em sala de aula: o papel do professor. In: de CARVALHO, A., M. P. (Org.). Ensino de Ciências por investigação: condições para a implementação em sala de aula. São Paulo: Cengage Learning, 2013.

SASSERON, L. H.; CARVALHO, A. M. P. Almejando a alfabetização científica no ensino fundamental: a proposição e a procura de indicadores do processo. Investigações em Ensino de Ciências, Porto Alegre, v. 13, n. 3, p. 333-352, 2008.

SASSERON, L. H.; CARVALHO, A. M. P. Construindo argumentação na sala de aula: a presença do ciclo argumentativo, os indicadores de alfabetização científica e o padrão de Toulmin. Ciência \& Educação, v. 17, n. 1, p. 97-114, 2011.

SILVA, M.G.L.; MARQUEZ, C.B.; OLIVERAS, B.P. Análisis de las dificultades de futuros professores de química ao leer críticamenteun artículo de prensa. Educação \& Pesquisa (no prelo).

TOULMIN, S. E. Os Usos do Argumento. 2ª ed. São Paulo: Martins Fontes, 2006.

VERHEIJ, B. Evaluating arguments based on Toulmin's scheme. Argumentation, 19, 347-371, 2005.

VON AUFSCHNAITER, C.; ERDURAN, S.; OSBORNE, J.; SIMON, S. Arguing to Learn and Learning to Argue: Case Studies of How Students' Argumentation Relates to Their Scientific Knowledge. Journal of Research in Science Teaching, vol. 45, n. 1, p. 101-131, 2008.

WATSON, J.; CRICK, F. Molecular Structure of Nucleic Acids. Nature, Vol. 171, no 4356, p. 737-738, April 30, 1953.

ZOHAR, A.; NEMET, F. Fostering students' knowledge and argumentation skills through dilemmas in human genetics. Journal of Research in Science Teaching, 39(1), p. 35-62, 2002.

Recebido: 28 set. 2016

Aprovado: 11 out. 2016

DOI: 10.3895/actio.v1n1.4745

Como citar:

SILVA, M. L. M.; SILVA, M. G. L da. Argumentação no Ensino de Biologia: uma experiência no ensino médio.

ACTIO, Curitiba, v. 1, n. 1, p. 70-86, jul./dez. 2016. Disponível em: <https://periodicos.utfpr.edu.br/actio>.

Acesso em: XXX.

Correspondência:

Marcos Leonardo Martins Silva

Rua Francisco Fernandes, n. 04, Capim Macio, Natal, Rio Grande do Norte, Brasil.

Direito autoral: Este artigo está licenciado sob os termos da Licença CreativeCommons-Atribuição 4.0

Internacional.

(c) (i) 